\title{
Conservation conundrums and the challenges of managing unexplained declines of multiple species
}

David B. Lindenmayer ${ }^{1,2}$

Jeff Wood ${ }^{1}$

Christopher MacGregor ${ }^{1,2}$

Claire Foster ${ }^{1}$

Ben Scheele ${ }^{1,2}$

Ayesha Tulloch ${ }^{1}$

Philip Barton ${ }^{1}$

Sam Banks ${ }^{1}$

Natasha Robinson ${ }^{1,2}$

Luke S. O’Loughlin ${ }^{1}$

Nick Dexter ${ }^{3}$

Sarah Legge ${ }^{2}$

${ }^{1}$ Fenner School of Environment and Society, The Australian National University, Canberra, ACT, 2601

${ }^{2}$ Threatened Species Recovery Hub, National Environmental Science Program, Fenner School of Environment and Society, The Australian National University, Canberra, ACT, 2601, Australia

${ }^{3}$ Parks Australia, Jervis Bay Territory, ACT, 2540, Australia

Running head: Quantifying and attempting to explain mammal assemblage collapse 


\title{
ACKNOWLEDGEMENTS
}

The work reported here has been supported by a range of institutions over the past 15 years including Parks Australia, the Department of Defence, The Australian Government (National Environmental Science Program), and the Australian Research Council. We thank Tabitha Boyer for assistance in preparing this paper. Comments by Martin Westgate considerably improved an earlier version of this paper.

\begin{abstract}
The conventional approach to conserving threatened biota is to identify drivers of decline, instigate actions to mitigate threatening processes, and monitor interventions to test their effectiveness and ensure target species recover. In Australia, predation by introduced predators is a threatening process for many native mammals. Here we report the results of a 15 year monitoring study in an iconic Australian reserve, Booderee National Park, where exotic Red Fox (Vulpes vulpes) populations have been controlled through an intensive poison baiting program since 2003. Unexpectedly, we documented the collapse of native mammal fauna during this period, including fully arboreal species that should be largely unaffected by fox predation - such as the nationally Vulnerable Greater Glider (Petauroides volans) and Common Ringtail Possum (Pseudocheirus peregrinus).
\end{abstract}

We used path analysis to explore potential causes of these unexpected declines. We found no compelling evidence to support hypotheses that competition with increasing native species, native predator release, or increases in native herbivores underpinned mammal declines. Beyond the path analysis, data from other studies completed both inside Booderee National Park and outside (where intensive fox baiting does not occur yet depleted fauna species 
remain), allowed us to rule out several drivers of change. The temporal declines we documented for arboreal marsupials were not anticipated nor explained by any clear mechanism.

We propose the use of experimentally-guided reintroductions and translocations to: (1) restore empty niches such as the currently vacant apex mammal predator niche, (2) reconstruct the now depleted arboreal marsupial guild, and (3) further test key hypotheses associated with mammal decline. We also suggest that given the potential for perverse outcomes following large-scale management interventions (even those where there is high confidence of success), wildlife managers should consider maintaining reference areas (where there is no management intervention). Finally, as the declines we documented were unexpected and rapid, there is a clear need to develop more sensitive early warning signals to alert conservation managers to impending problems, allowing them to alter management regimes before major declines occur.

Keywords: Biodiversity collapse, long-term monitoring, exotic predator control, mammal decline, ecological surprises, novel assemblages, experimental reintroduction, novel management interventions

\section{INTRODUCTION}

Conservation biology aims to address biodiversity loss through identifying key threats driving species declines (Lindenmayer and Burgman 2005; Johnson et al. 2017), applying threat mitigation actions, and establishing monitoring programs to determine if management practices are effective (Tilman et al. 2017). The underlying premise of this approach is that removing the drivers of decline should result in the recovery of the target species (Caughley 
and Gunn 1996; Lindenmayer and Hunter 2010). However, sometimes the removal of what is thought to be a key threat does not lead to recovery, or worse, is associated with further declines of target and non-target native species (e.g. Zavaleta et al. 2001; Lampert et al. 2014). This may occur because interactive threats are occurring (e.g. Doherty et al. 2015). Indeed, there are a number of cases where well-intentioned conservation interventions aimed at mitigating threats have led to unexpected and perverse outcomes (e.g. Taylor 1979; Bergstrom et al. 2009). Often, increases in the threat itself occurs after management due to overcompensation (an increase in abundance in response to harvest; e.g. (Lazenby et al. 2015) and instability (population cycling) (Zipkin et al. 2009). For example, actions to control some invasive species have led to increases in the threat (Pardini et al. 2009; Zipkin et al. 2009). In other examples, successful removal of a threat facilitated the establishment of a second threat (McGregor et al. 2014) such as a secondary weed invasion. Understanding the reasons for unforeseen outcomes is critical not only for evaluating management (Walsh et al. 2012), but also to accurately inform future management plans and allocate scarce conservation funds to achieve positive conservation benefits.

Australia has a long record of targeted management designed to recover the nation's numerous threatened species (Garnett et al. 2018). In the case of mammals, a group characterized by a loss of approximately $10 \%$ of native terrestrial species over the last 200 years (Woinarski et al. 2015), the control of invasive carnivores such as the Red Fox (Vulpes vulpes) and the Feral Cat (Felis catus) has been an important form of management. Feral predator control is widely considered to be a key component of best practice management in many Australian protected areas (Braysher 2017). For example, there are plans to substantially reduce populations of exotic predators using intensive poison bating and other control methods across 12 million ha of Australia (Australian Government 2015). While Red Fox control has demonstrated conservation value (e.g. Kinnear et al. 1988), some recent 
studies have documented perverse outcomes associated with their removal (Marlow et al. 2015), potentially attributed to meso-predator release of feral cats (Wayne et al. 2017).

Here we report the results of a 15 year mammal monitoring study in an iconic reserve, Booderee National Park, in south-eastern Australia. Monitoring commenced at the same time as an intensification of a poison baiting program aimed at reducing Red Fox abundance to conserve native mammal populations. Baiting reduced Red Fox abundance, but rather than leading to native mammal population recovery, we observed unexpected severe declines and local extinctions in terrestrial and arboreal mammals. We used our monitoring datasets to test empirical support for different hypotheses that might explain the observed temporal trajectories. We discuss general lessons emerging from this study including determining ways to manage biodiversity when drivers of decline remain unclear.

\section{METHODS}

\section{Study area}

Our work was focused within and around Booderee National Park in south-eastern Australia (Figure 1) which is a 6600 ha IUCN Category I reserve that supports more than 205 terrestrial vertebrate species, including threatened taxa and threatened ecological communities (Lindenmayer et al. 2014). Four species of large terrestrial mammalian predators either recently occurred in the park but are now locally extinct, or extremely rare (Spotted-tailed Quoll Dasyurus maculatus last seen in the mid-1980s; M. Fortescue, personal communication; Dingo/dog Canis spp. rarely seen in the last 15 years), or are likely to have prehistorically occurred in the region but are now globally extinct (Thylacine Thylacinus cyanocephalus), or regionally extinct (Tasmanian Devil Sarcophilus harrisii). 


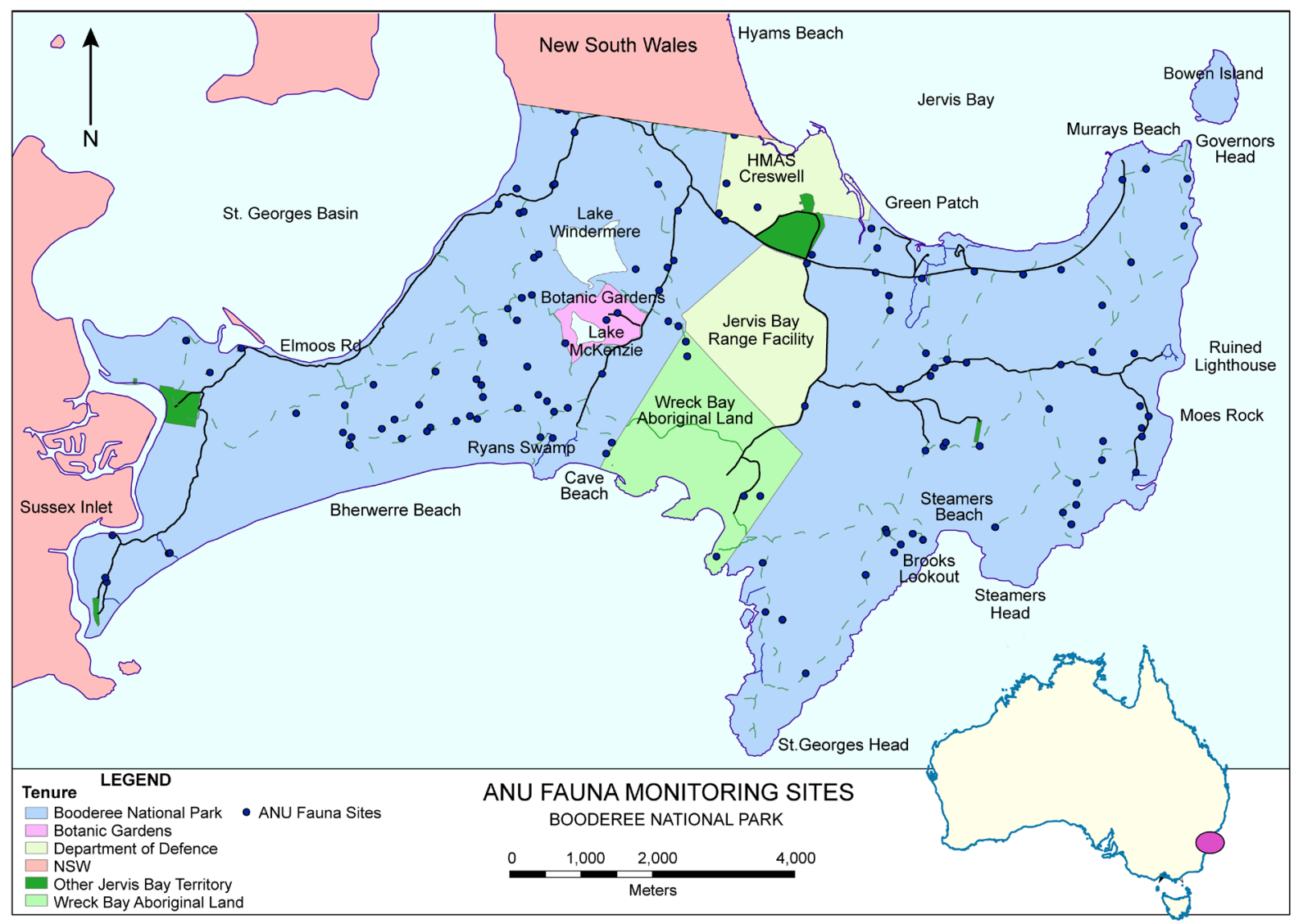

\section{Figure 1. The location of long-term field survey sites at Booderee National Park.}

Booderee National Park is ranked as one of Australia's best-managed protected areas (WWF Australia 2008) and the control of processes threatening biodiversity is a key part of the plan of management for the reserve (Lindenmayer et al. 2013). The park's management program includes an intensive poison baiting program to control populations of the Red Fox. A large wildfire burnt half the park in 2003 , however, subsequent analysis has demonstrated that the majority of fauna were either minimally affected by this fire event or have since recovered (Lindenmayer et al. 2016a). Overlaid on these management programs, has been a monitoring program that has run since 2003. The monitoring work has quantified patterns of temporal change in a range of vertebrate groups including mammals, birds, reptiles and frogs, as well as native vegetation (Lindenmayer et al. 2014). The focus of this paper is mammals 
because major changes in site-level species richness and losses of individual species have not been observed for other monitored vertebrate groups. The individual mammal species examined were the following arboreal marsupials: Greater Glider (Petauroides volans), Common Ringtail Possum (Pseudocheirus peregrinus), Sugar Glider (Petaurus breviceps), Common Brushtail Possum (Trichosurus vulpecula), the scanscorial Brown Antechinus (Antechinus stuartii), the ground-dwelling Bush Rat (Rattus fuscipes), Swamp Rat (Rattus lutreolus), Eastern Chestnut Mouse (Pseudomys gracilicaudatus), Long-nosed Bandicoot (Perameles nasuta) and the macropods: Eastern Grey Kangaroo (Macropus giganteus), Black Wallaby (Wallabia bicolor) and Red-necked Wallaby (Notamacropus rufogriseus).

\section{Study design}

We established 129 permanent monitoring sites across the seven key vegetation types in Booderee National Park (Figure 1) - warm temperate rainforests, forests, woodlands, heathlands, shrublands, swamps and sedgelands. We employed a stratified, randomized and replicated process to distribute long-term monitoring sites widely throughout the study area. This was to limit the potential for geographic bias in our results. We replicated sites within each vegetation type with a focus on replicating the most common classes. The number of samples was generally proportional to the total area occupied by each vegetation class

We established a permanent 100 metre long transect at each of our 129 sites. We used 100 metre transects because of high heterogeneity in vegetation cover at Booderee National Park, where changes in vegetation type often occur over a short distance (Stirnemann et al. 2014). Transect lengths in excess of 100 metres would have resulted in many transects spanning two vegetation types. We ensured that each transect was confined to a single vegetation type.

\section{Fox baiting and control program}


A control program for the Red Fox, an exotic carnivore that occupies the apex mammal predator niche in our study system, was first implemented in 1999 with 120 stations (each measuring $10 \mathrm{~m}$ x $10 \mathrm{~m}$ ) baited every six months. Bait stations were located in all vegetation types and dispersed widely throughout Booderee National Park. Data on bait take were gathered each time the bait station was checked and new baits were laid. Control efforts were greatly intensified in 2003 with baits laid monthly to 2014 and then fortnightly to the present day. Allied with the fox baiting program, a network of $2 \mathrm{~m}$ x $2 \mathrm{~m}$ sand plots was established throughout Booderee National Park and footprints, tracks and scats of all animals detected in these plots were recorded every month. Since 2015, remote cameras have been deployed at 50 locations distributed widely across the eastern and eastern parts Booderee National Park. Cameras were deployed for 14 nights per site each year. If a fox is detected, a professional marksman was deployed.

\section{Field surveys of terrestrial and scansorial mammals}

Each of our 129 monitoring sites consisted of star picket markers set at $0 \mathrm{~m}, 20 \mathrm{~m}, 40$ $\mathrm{m}, 60 \mathrm{~m}, 80 \mathrm{~m}$ and $100 \mathrm{~m}$ points along a permanent transect. Our trapping protocols at each site involved opening along the transect for three consecutive days/nights, ten Elliott box traps $(10 \mathrm{~cm} \times 10 \mathrm{~cm} \times 30 \mathrm{~cm}$; Elliott Scientific Equipment, Upwey, Victoria) at $10 \mathrm{~m}$ intervals and four small $(20 \times 20 \times 50 \mathrm{~cm})$ and two large $(30 \times 30 \times 60 \mathrm{~cm})$ wire cage traps. We baited all traps with a mixture of peanut butter and rolled oats. We completed trapping surveys in the summer of all years between late 2003 and 2016, surveying approximately 75 sites each year.

\section{Field surveys of arboreal marsupials and owls}

We counted arboreal marsupials by repeated spotlighting along each permanent transect established at each of the 129 sites in our study. Calls and spotlight detections of owls also 
were recorded as part of surveys. We did not undertake spotlighting on nights of poor weather (rain, high wind, fog or heavy cloud cover). We completed spotlighting surveys in 10 years over a 15-year period - 2003, 2004, 2005, 2006, 2007, 2009, 2011, 2013, 2015 and 2017.

\section{Statistical analysis}

We present our analyses in two stages. First, we document temporal patterns in mammal detections as evidence of our claim that overall species richness and many individual species have declined. Second, we evaluate evidence for various potential mechanisms/processes underpinning the patterns we observed.

In the first step of our analysis, we modelled temporal changes in mammal species richness and the occurrence of individual species of mammals as well as for owls (all species combined). For mammal species richness and for each of the individual mammal species, we fitted a quasi-Poisson generalized linear mixed model (GLMM).to the count data for each site and with both site and year fitted as random effects. We fitted a quadratic regression spline to time with a knot halfway through the period of observation to give a smoothed summary of the data for each variable. For all analyses, we tested the effects of vegetation type by fitting a categorical variable with seven levels (corresponding to the seven major vegetation classes in Booderee National Park). When a given species was never recorded in a particular vegetation type, we excluded the relevant sites from the analysis (e.g., the Greater Glider was absent from heathlands, swamps and sedgelands). We also fitted models with only a linear effect of time plus random effects of both site and time to test for long-term decline.

We fitted a GLM to the counts of poison baits taken at each sampling time. We used a quasi-binomial model with a logit link, and fitted a quadratic regression spline in time with a knot at the midpoint of the count times. For fox detections in sand plots, we fitted a GLMM 
assuming a Poisson distribution with a logarithmic link and with site as a random effect. We also fitted terms for time of year, first half versus second of the monitoring period (because fox activity is known to vary seasonally), and for the east versus the west of Booderee National Park (because foxes might be expected to be more commonly detected at the entrance to park on a peninsula).

The second part of our statistical analysis entailed a series of path analyses (Shipley 2009) to explore evidence for four potential pathways to explain observed temporal trends in counts of individual species. We examined these pathways based on expert knowledge of the ecology of Booderee National Park. We excluded two species (the Greater Glider and the Eastern Chestnut Mouse) from the path analysis because of insufficient data for the more complex models required in this analysis. In addition, we combined records of the Black Wallaby, Eastern Grey Kangaroo and Red-necked Wallaby (denoted as “macropods”). The four pathways we examined were:

A. A reduction in fox numbers triggered an increase in owls with subsequent impacts on their mammal prey (Figure 2a). Large owls like the Powerful Owl (Ninox strenua) and Sooty Owl (Tyto tenebricosa) are predators of mammals which are also prey for foxes (e.g. the Common Ringtail Possum [(see Roberts et al. 2006)]), and so might be expected to benefit from feral predator control.

B. An increase in the hollow-dependent Common Brushtail Possum following a decline in foxes, with the Common Brushtail Possum then outcompeting other hollow-dependent species such as the now extinct facultative hollow-user, the Common Ringtail Possum (Figure 2b).

C. An increase in macropods following a reduction in numbers of the Red Fox due to reduced predation pressure on juveniles (Dawson 2000). Increased macropods may then have had 
negative effects on cover-dependent ground-dwelling animals such as the Long-nosed Bandicoot, Bush Rat and Brown Antechinus through browsing-related changes in vegetation cover leading to reduced habitat suitability and/or increased predation risk by native predators (e.g. owls, snakes) due to a loss of vegetation cover (Figure 2c) (Foster et al. 2016).

D. The effect of fire with a major conflagration in Booderee National Park being in 2003, and which burned approximately $50 \%$ of the vegetation in the reserve (Lindenmayer et al. 2016a). Many mammal species have known associations with time since fire (Figure 2d).

The parameters for the path model included: (1) activity of the Red Fox, measured by the amount of fox bait take (given that detections in sand plots showed the same temporal pattern as the bait take data; see Figure 3a and 3b), (2) large herbivores, quantified through detections of macropods (all species combined), (3) native terrestrial and arboreal mammal species (4) native avian nocturnal predators, quantified through detections of the large forest owls (all species combined), (5) fire, including time since fire and the severity of the last major fire (in 2003) in Booderee National Park. The predictor variables were standardized to have unit variance so that the regression coefficients for the different predictors were directly comparable. For this analysis, site was fitted as a random effect. We initially fitted an effect of time as both a linear and also a quadratic effect (to account for non-linear temporal patterns in species abundance). However, time and fox bait take were strongly related. Initial modelling was also complicated by the fact that fire severity data were available only for the 2003 wildfire. We therefore elected to run subsequent path models without time and fire severity as variables.

The full path model we examined is presented in Figure 2e. After running this full model, for each response variable we fitted all possible subsets of the predictors. We selected the final model using the Bayesian Information Criterion. 
A. Altered native predators

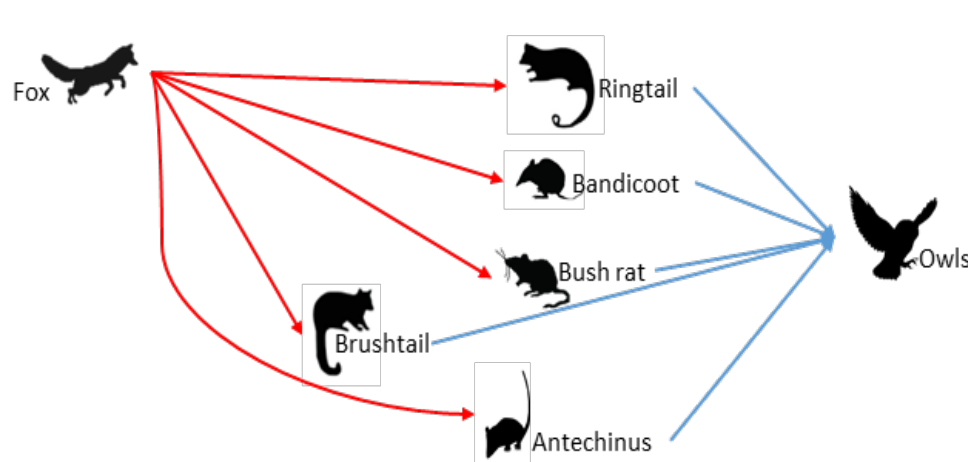

B. Increased competition with brushtail possum (hollows and/or food resources)
C. Increased macropods, reduced vegetation cover, and reduced plant food resources

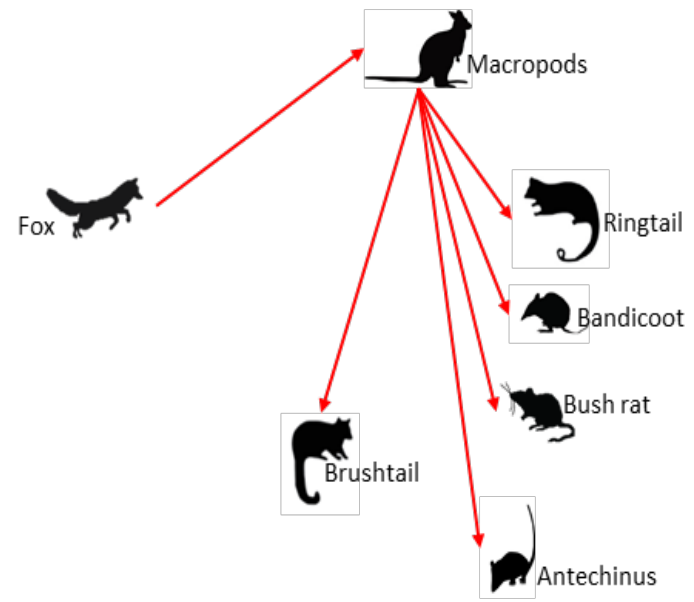

D. Response to major fire event

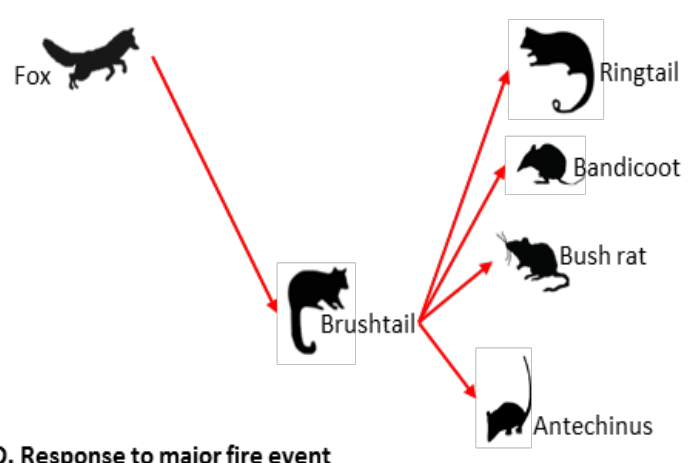

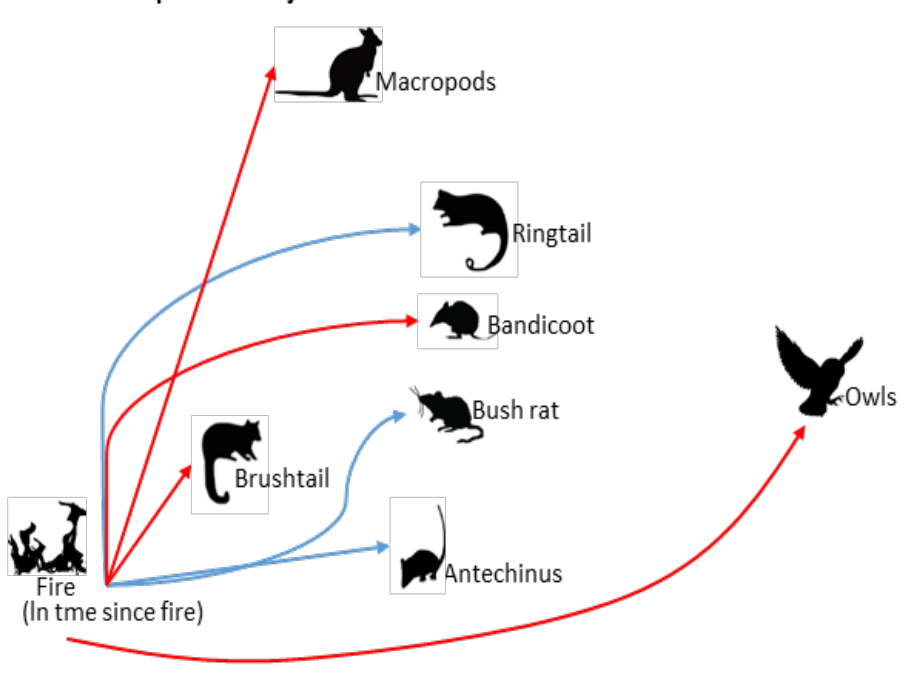

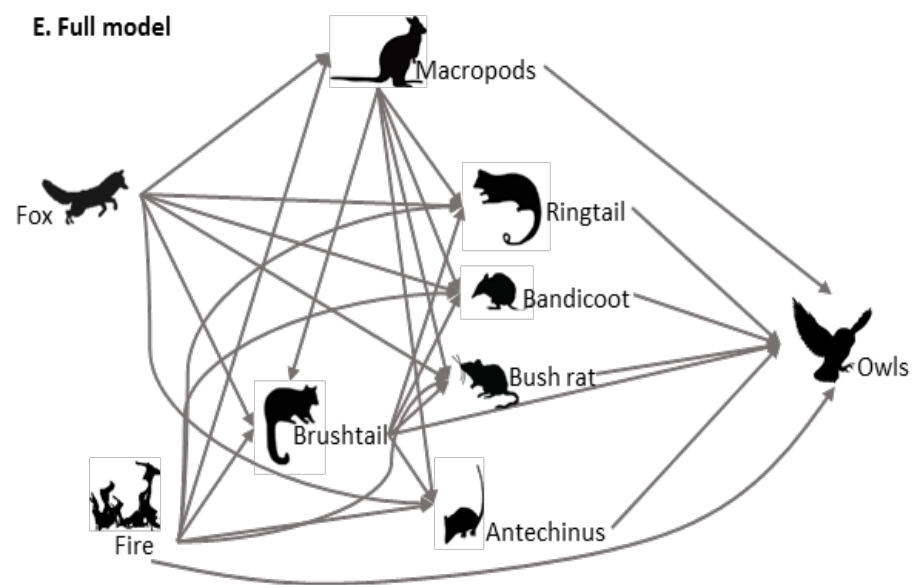

Figure 2. Potential pathways underpinning the decline of native mammals at Booderee

National Park A) increase in native predators, B) competition with the Common

Brushtail Possum, C) increased native herbivore pressure, (D) response to a large

wildfire, and (E) the full model tested using path analysis. The Greater Glider and the

Eastern Chestnut Mouse were excluded from path analysis because of insufficient data.

The red and blue lines correspond to predicted negative and positive associations, respectively. 


\section{RESULTS}

Temporal changes in fox bait take and sand plot detections

There was a significant temporal decline in bait take $\left(\mathrm{F}_{3,94}=118 ; \mathrm{P}<0.001\right)$, dropping from $>80 \%$ in 1999 , to $50 \%$ in 2003 and consistently below $15 \%$ thereafter (Figure 3a). Records of fox tracks in sand plots also exhibited a highly significant decline $\left(\chi_{3}^{2}=220.2 ; \mathrm{P}\right.$ $<0.001$ ) (Figure 3b) similar to that observed for bait take. The data suggest a slight increase in the number of detections of foxes toward the end of the survey period, although detections remained substantially below numbers at the outset of fox control efforts (Figure 3). There was no evidence of significant spatial dependence in either bait take or sand plot records of foxes.
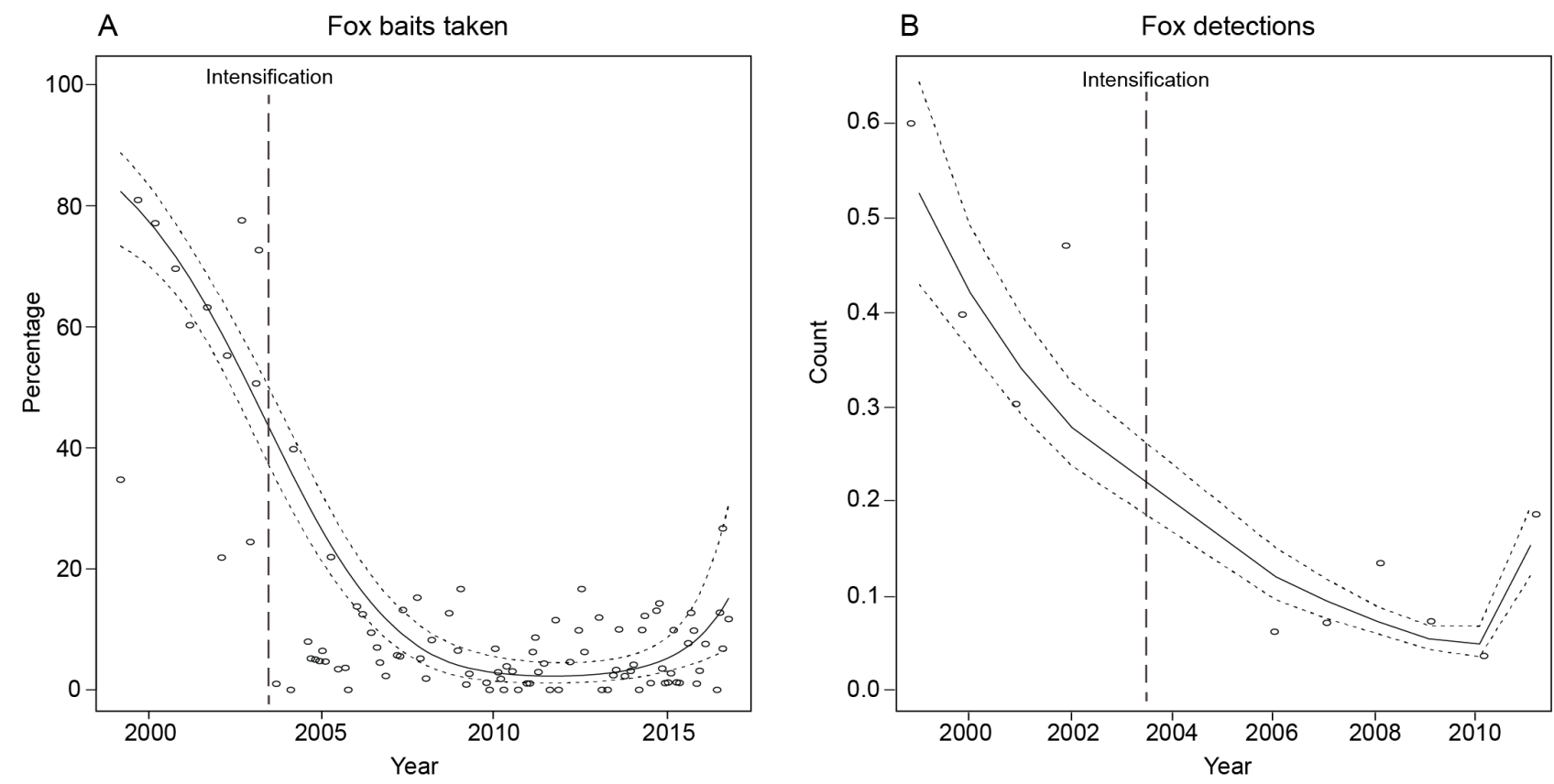

Figure 3. Temporal changes in detections of foxes. A. Bait take based on data gathered

from 120 poison bait stations located throughout Booderee National Park. Bait take trend patterns are shown following the instigation of poison baiting in 1999 and then the 
intensification of the red fox control program in 2003. The temporal trend is highly significant $(P<0.001)$. B. Detections of foxes in sand plots at Booderee National Park. The temporal trend is highly significant $(P<0.001)$. Collection of sand plot data did not continue beyond $2013.95 \%$ confidence intervals for the fitted lines are included.

The Feral Cat is rare in Booderee National Park with only 21 records between 1999 and 2013 (when sand plot monitoring ceased). There was no evidence of a temporal increase in the Feral Cat with a decline in the Red Fox, nor were cats recorded in camera traps following the cessation of sand plot monitoring.

Temporal changes in mammal and records of large forest owls

Site-level native mammal species richness (defined as the number of different species recorded in trapping surveys) almost halved between 2003 and $2016\left(\mathrm{~F}_{1,11}=66 ; \mathrm{P}<0.001\right)$ (Figure 4). There was evidence of non-linear patterns of temporal change in 5 of the 12 species in which detections first increased in the early years of monitoring (2003-2009), and then declined thereafter (Figure 4). We uncovered compelling evidence for a significant decline in the canopy-dwelling arboreal marsupial, the Greater Glider, $\left(\mathrm{F}_{1,4}=27.8, \mathrm{P}=0.006\right)$, and likely local extinction, as it has not been observed in Booderee National Park since 2006 (Figure 4). The arboreal generalist omnivore, the Common Ringtail Possum also declined significantly $\left(\mathrm{F}_{1,13}=52.6, \mathrm{P}<0.001\right)$ and has not been detected since 2014 (Figure 4). The Long-nosed Bandicoot initially increased but then declined significantly $\left(\mathrm{F}_{1,14}=16.4\right.$, $\mathrm{P}=0.001$ ) and is now rare (detected at $<4 \%$ of sites in 2016 compared with $33 \%$ of sites in 2003) (Figure 4). Other species exhibiting significant declines include the ground-dwelling Bush Rat (Rattus fuscipes) $\left(\mathrm{F}_{1,16}=92.5, \mathrm{P}<0.001\right)$ which has declined from occurring at $92 \%$ in 2003 to $48 \%$ of sites in 2016 and the scansorial micro-predator, the Brown Antechinus 
(Antechinus stuartii), $\left(\mathrm{F}_{1,14}=13.6, \mathrm{P}=0.003\right)$ (Figure 4) which occurred at 53\% of sites in 2016 relative to $80 \%$ of sites in 2003 .

There were increases in detection of two species of macropod herbivores (the Eastern Grey Kangaroo [Macropus giganteus] and the Black Wallaby [Wallabia bicolor]) between 2003 and 2009, with populations oscillating slightly since then but staying $20 \%$ higher than initial levels (Figure 4). The Common Brushtail Possum has increased since $2003\left(\mathrm{~F}_{1,13}=35.3\right.$, $\mathrm{P}<0.001$ ) and was recorded from $30 \%$ of sites in 2017 relative to $8 \%$ of sites in 2003 (Figure 4).

No significant temporal trends were observed in the Swamp Rat (Rattus lutreolus) and the Eastern Chestnut Mouse (Pseudomys gracilicaudatus) for which numbers of detections in 2016 were similar to those in 2003 (Figure 4). The abundance of the Sugar Glider in 2017 (Petaurus breviceps) also was similar to that recorded in 2003 (Figure 4).

We recorded five species of owls during the 15 years of our study; the Powerful Owl (Ninox strenua), Sooty Owl (Tyto tenebricosa), Masked Owl (Tyto novaehollandiae), Boobook Owl (Ninox novaeseelandiae), and Barn Owl (Tyto alba). There have been no records of the Powerful, Sooty or Masked Owls since 2013. P-values have not been provided for these species because they were insufficient data to complete statistical analyses of temporal trends. 
A Trapping species richness

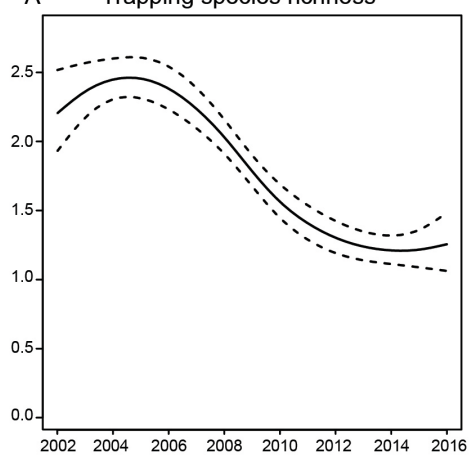

D Common Brushtail Possum
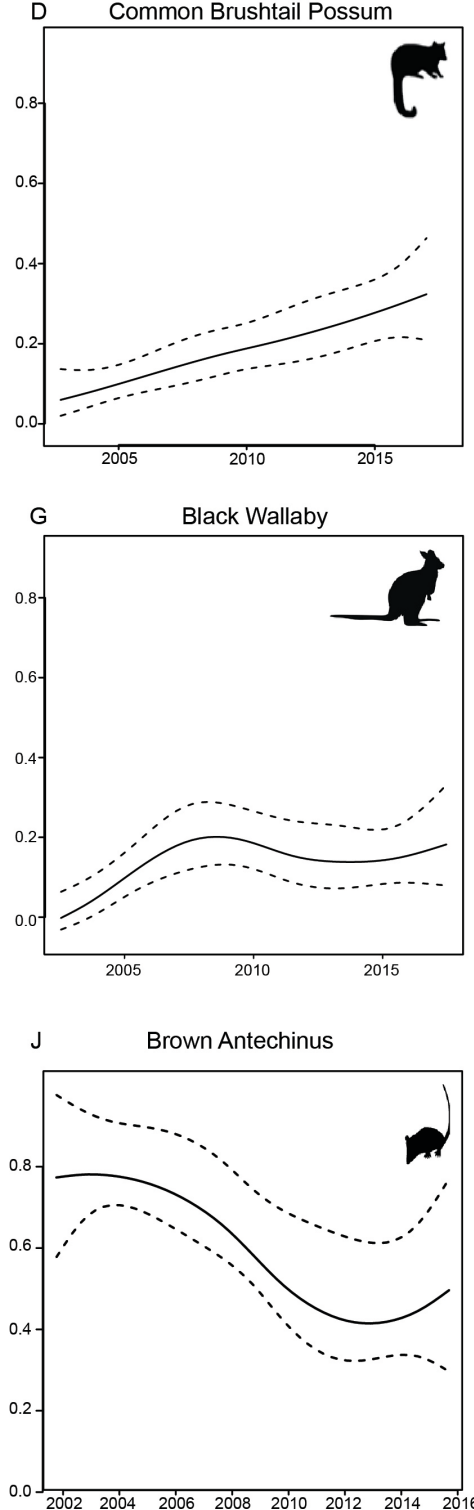

B

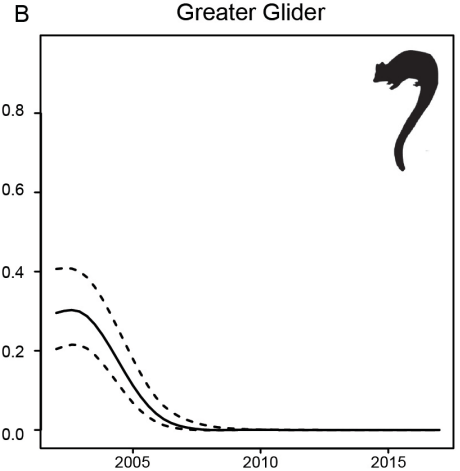

Sugar Glider
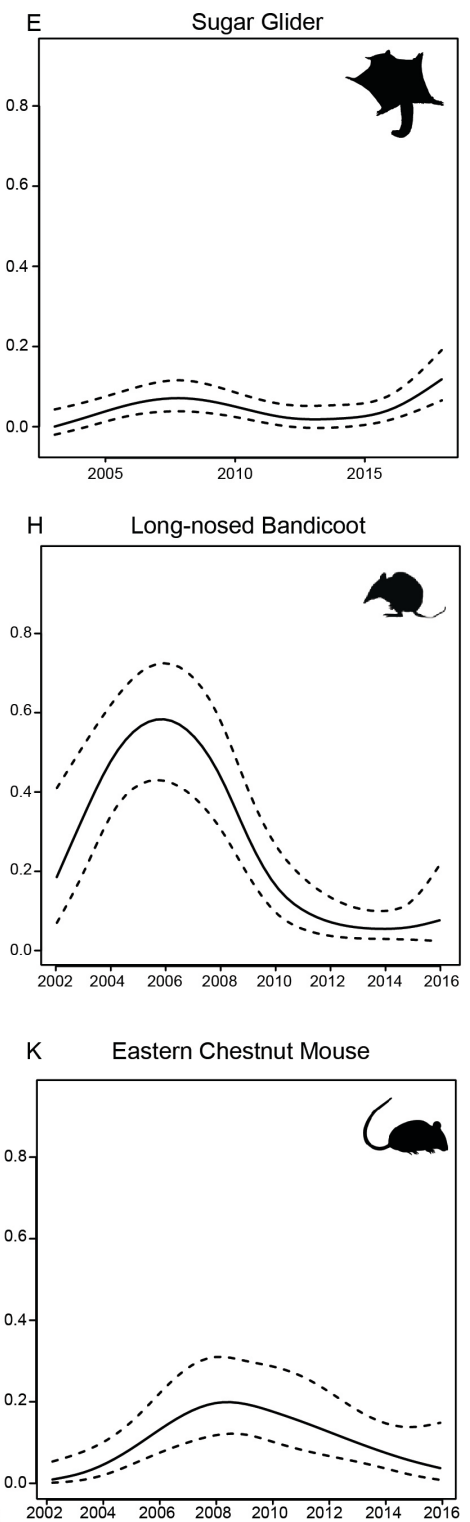

M Composite Owls

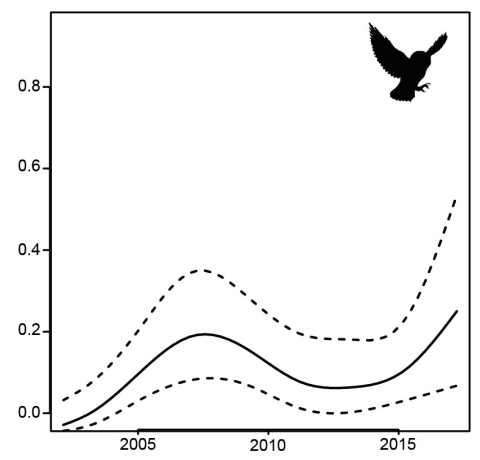

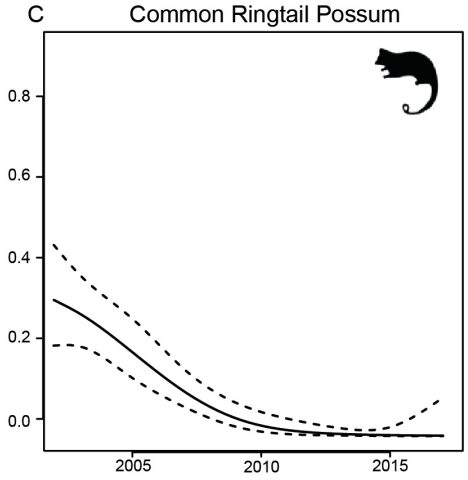
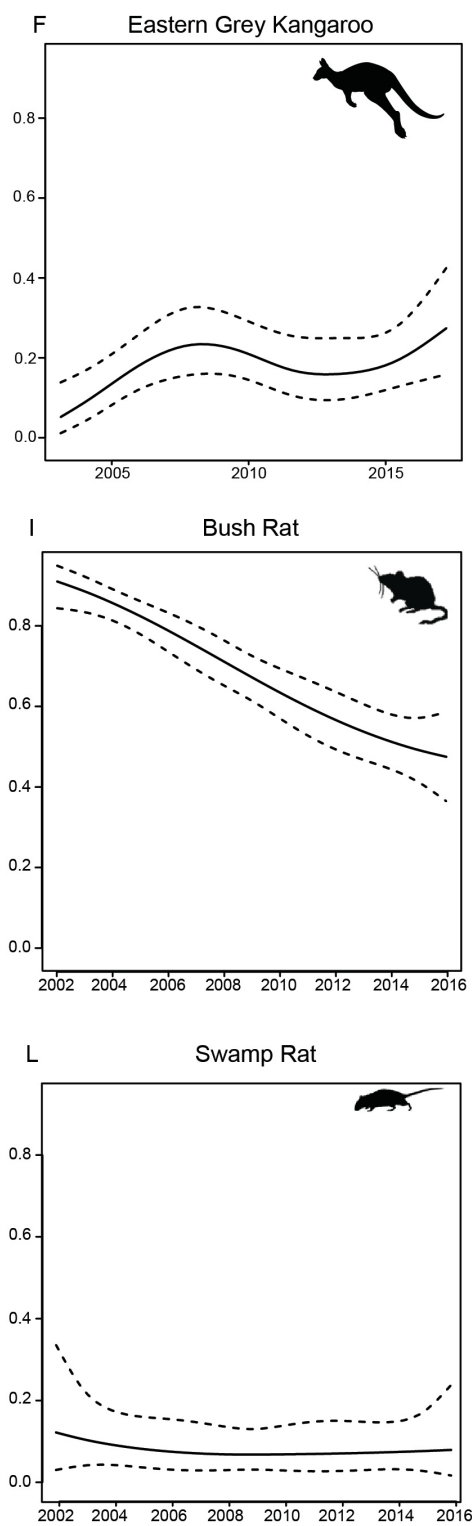
Figures 4a-m. Temporal changes in site-level. A. Species richness based on trapping. Parts B-M of the figure show the probability of occurrence (and associated confidence intervals) of mammals and owls in Booderee National Park. The plots are derived from fitting regression splines to presence/absence data for each site in each survey year (see $\underline{\text { text). }}$

Path analysis to explore mechanisms underpinning mammal decline

The occurrence of macropods and the Common Brushtail Possum were both negatively associated with fox bait take, which is consistent with a direct effect of foxes on these species. The Long-nosed Bandicoot also was negatively associated with fox bait take, and negatively associated with increasing time since fire, consistent with both the direct effect of foxes and the large fire event hypotheses, respectively (Fig. 2d). By contrast, the Common Ringtail Possum, Bush Rat and Brown Antechinus were all positively associated with fox bait take, the opposite of predictions under the direct effect of the fox hypothesis. The Common Ringtail Possum was also positively associated with the occurrence of the Common Brushtail Possum, in contradiction with the competition with the Common Brushtail Possum hypothesis (Fig. 2b). Macropod occurrence was negatively associated with increasing time since fire, as predicted under the wildfire hypothesis (Fig 2d). The Bush Rat exhibited a negative association with the occurrence of the Common Brushtail Possum, as was expected under the increased competition hypothesis (Fig. 2b). There was no evidence in support of either the elevated native predator hypothesis or the increased macropod (and reduced vegetation cover) hypothesis or, other than a negative association between the occurrence of the Long-nosed Bandicoot and macropods. 


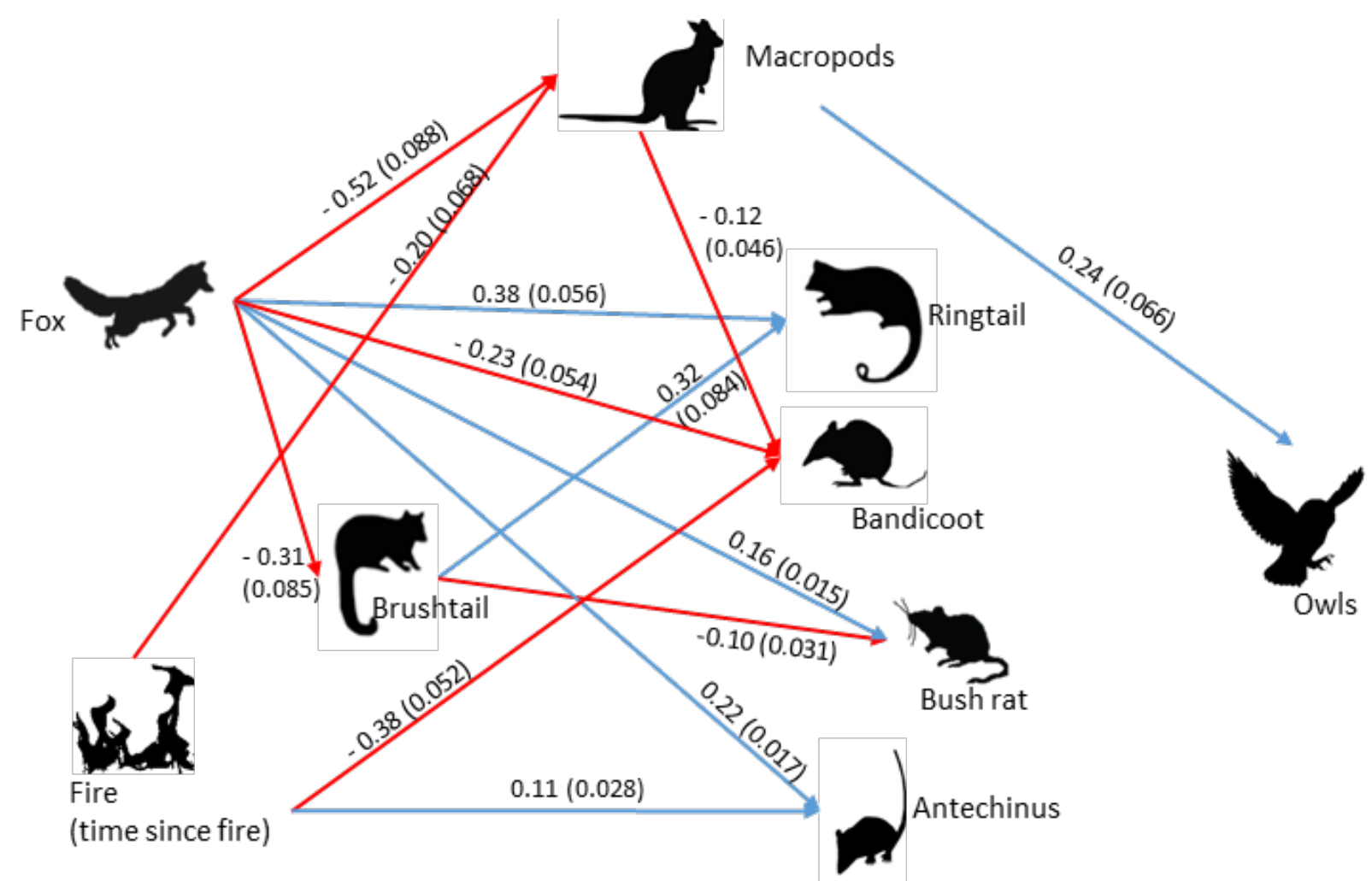

Figure 5. Simplified path model including only significant paths and coefficients with associated standard errors. Coefficients from the full model are presented in Appendix 1. Significant positive effects are shown in blue and significant negative effects in red. The Greater Glider and the Eastern Chestnut Mouse are not included because there were insufficient data to include them in path analysis.

\section{DISCUSSION}

Australia has been characterized by a significant loss of its terrestrial mammal fauna, with exotic carnivores implicated in the decline or extinction of many species (Woinarski et al. 2015). Exotic predator control is therefore a major focus of conservation efforts (Australian Government 2015; Legge et al. 2017). This is the case in the iconic Booderee National Park, where a fox baiting program was intensified in 2003 (Roberts et al. 2006), with commensurate significant reductions in the rate of bait take and sand plot detections of foxes within the park (Figure 3). Unexpectedly, the response of the mammal fauna to this successful predator control program was not consistently positive. Macropods and the 
Common Brushtail Possum increased as expected, and as reported in other studies following exotic predator control (e.g. Murray et al. 2006). In contrast, there were significant declines in several other native mammal species that were expected to respond positively to fox control (Figure 4).

Unexpected outcomes following invasive predator management in our study include simplified assemblages of arboreal mammals, declines in ground-dwelling mammals, and vacant niches due to local extinctions. Vacant niches within the park now include a specialist folivore (the Greater Glider) and a generalist omnivore (Common Ringtail Possum). The generalist exudivore (the Sugar Glider) is only rarely observed, although it was once common (Howard 1989). Only the Common Brushtail Possum remains a common (Figure 4) and widespread member of the arboreal mammal assemblage. The nocturnal avian predator guild is now also heavily depleted with none of the three species of large forest owls (the Powerful Owl, Sooty Owl and Masked Owl) having been recorded in surveys since 2013, despite once being relatively common in the region (Debus 1997). The absence of key prey species is the most likely explanation for the loss of nocturnal avian predators (see Korpimaki 1985).

The ground-dwelling Long-nosed Bandicoot initially increased commensurate with intensified predator control, and then declined (Figure 4); this is a pattern similar to that observed for the Woylie (Bettongia penicillata) in southern Western Australia after intensive fox-baiting (Wayne et al. 2017). In the case of the Woylie, meso-predator release - in populations of the Feral Cat - were implicated in species decline (Wayne et al. 2017). However, cats are extremely rare in Booderee National Park and are highly unlikely to be the driver of declines we have quantified (see Table 1, Appendix 2). Notably, there has been no evidence for the release of other meso-predators (Table 1). In the remainder of this section, we explore some of the evidence for particular mechanisms underpinning observed declines. 
We conclude with some general lessons associated with complex conservation challenges arising from unexpected and unexplained declines of native biota.

\section{Potential mechanisms underpinning temporal change in mammals}

Many of the declines we documented were counter-intuitive and opposite to patterns that might be expected from pre-existing ecological knowledge. The Common Ringtail Possum - a major prey item of foxes (Roberts et al. 2006) was expected to benefit from fox control, but declined substantially over the survey period and has not been detected since 2014. Other well-known prey species of foxes also declined significantly (Figure 4) but which might have been expected to increase under fox control These included the Longnosed Bandicoot (Triggs et al. 1984; Meek and Triggs 1998) which became highly abundant before populations crashed, consistent with some theoretical models of species responses (e.g. see May 1981). Another species which declined significantly was the Bush Rat. Notably, other studies found that this species does not increase after fox control (see Banks 1999; Kovacs et al. 2012), although they did not decline, as occurred in our investigation. The Greater Glider is a specialist arboreal folivore that almost never descends from tree canopies, and is only very rarely a prey item for the largely terrestrial red fox (Triggs et al. 1984). This species was not expected to respond positively or negatively to fox control, but instead it declined rapidly and is now locally extinct.

We employed path analysis to explore evidence for potential pathways contributing to temporal changes in the abundance of particular species. We found no strong evidence to support the hypothesis that increases in alternative native predators (owls) contributed to species declines (Fig. 2a, Fig. 5). There was no association between owls and the occurrence of the Common Ringtail Possum (Figure 5) as might be expected if a temporary increase in owl abundance contributed to these species declines. Similarly, we found limited evidence to 
support the hypothesis that increased abundance of native herbivores contributed to declines, via resource competition or reduced habitat quality (Figure 2c). Herbivores such as macropods increased following the intensification of poison baiting (Figure 3) but path analyses revealed no association between macropods and other species including other ground-dwelling mammals like the Brown Antechinus and Bush Rat. The exception was the Long-nosed Bandicoot for which there was a negative association with macropods (Figure 5).

Path analysis contained no support for the hypothesis of competition between the Common Brushtail Possum and arboreal mammals. The Common Ringtail Possum was positively, not negatively, associated with occurrences of the Common Brushtail Possum (Fig. 5). Among the ground-dwelling mammals, there was some evidence to suggest an association between a decline in the Bush Rat, and an increase in the Common Brushtail Possum. This might indicate recourse competition between these two species, however, precise mechanisms for this association remain unclear.

Our path analysis produced some perplexing results such as the positive association between the abundance of foxes and the Common Ringtail Possum, the Bush Rat, and the Brown Antechinus (Figure 5). We suggest these patterns may be an artefact of concurrent temporal changes (i.e. declines) of these species, rather than a causal relationship. In the case of the Common Ringtail Possum, the absence of observations of the species after 2012 limited the ability to determine if temporal changes in abundance are associated with other factors (such as other species or fire). On this basis, we re-ran the path analysis using data only until 2012 but still no additional associations were uncovered and the reasons for decline remain unresolved.

Beyond the four pathways explored using path analysis, data from other studies completed outside Booderee National Park (Villaseñor et al. 2014; Villaseñor et al. 2015) 
(where all of the species which feature in this study are extant and intensive fox control does not occur), as well as monitoring data within Booderee National Park, allowed us to tentatively rule out several potential threatening processes as drivers of declines (see Table 1 and Appendix 2 for further commentary). For example, meso-predator release is unlikely, as there was no evidence of increases in feral cats, or other terrestrial meso-predators during the study period. Similarly, there has been no increase in small exotic predators like the Black Rat (Rattus rattus) or House Mouse (Mus musculus), all of which are rarely detected in Booderee National Park (Table 1). There also was no evidence that other possible drivers have underpinned the declines including consumption of poison baits, fire, weed infestation, and climate change (see Table 1, Appendix 2). Differences between the shapes of response curves for arboreal marsupials and ground-dwelling (see Figure 4) suggest that different (unknown) factor(s) may be influencing temporal changes of these two groups.

Table 1. Potential mechanisms or drivers of species decline and/or extinction in

Booderee National Park, and a summary of evidence ruling out the driver for quantified collapse in mammal and owl fauna. Further commentary on the reasons why these potential mechanisms can be ruled out is provided in Appendix 2. Note that we are exploring only independent processes and trying to provide explanations for them each separately, but interactive effects may be important (see text).

\begin{tabular}{|l|l|}
\hline $\begin{array}{l}\text { Potential } \\
\text { driver/mechanism }\end{array}$ & Evidence ruling out a given driver/mechanism \\
\hline $\begin{array}{l}\text { Competition among } \\
\text { hollow-using species }\end{array}$ & $\begin{array}{l}\text { There is no evidence that competition for tree hollows by the } \\
\text { Common Brushtail Possum led to the local extinction of the } \\
\text { Common Ringtail Possum and the Greater Glider. The Greater } \\
\text { Glider was lost from vegetation types where the Common } \\
\text { Brushtail Possum is rare, and declined before increases in the } \\
\text { Common Brushtail Possum (compare sub-diagrams in Figure } \\
\text { 4). The decline of the Common Ringtail Possum did occur as } \\
\text { the Common Brushtail Possum increased. However, the } \\
\text { Common Ringtail Possum is able to construct dreys as well as } \\
\text { occupy hollows (Lindenmayer et al. 2008), which makes this } \\
\text { explanation alone unlikely. }\end{array}$ \\
\hline
\end{tabular}




\begin{tabular}{|c|c|}
\hline $\begin{array}{l}\text { Native herbivore release } \\
\text { and over-browsing }\end{array}$ & $\begin{array}{l}\text { Initial increases in native herbivorous macropods were } \\
\text { associated with a decline in foxes (Figure 5). An experiment } \\
\text { at Booderee National Park has uncovered evidence of } \\
\text { negative effects of macropods on the Brown Antechinus } \\
\text { (Foster et al. 2016). However, path analysis contained no } \\
\text { evidence of an association between macropods and ground- } \\
\text { dwelling mammals, except for the Long-nosed Bandicoot } \\
\text { (Fig. 5). In addition, increases in ground-dwelling herbivores } \\
\text { are unlikely to influence fully arboreal mammals such as the } \\
\text { Greater Glider and Common Ringtail Possum. }\end{array}$ \\
\hline $\begin{array}{l}\text { Native predator or native } \\
\text { mesopredator release }\end{array}$ & $\begin{array}{l}\text { There is no evidence of a significant increase in large owls. } \\
\text { Sand plot data (Appendix 2) and reptile survey data } \\
\text { (Lindenmayer et al., unpublished data) do not show a } \\
\text { significant increase in large snakes; goannas do not occur at } \\
\text { Booderee National Park. }\end{array}$ \\
\hline $\begin{array}{l}\text { Exotic mesopredator or } \\
\text { exotic rodent release }\end{array}$ & $\begin{array}{l}\text { There have been very few detections of the feral cat } \\
\text { (Appendix 2) or feral pig (Sus scrofa). Unpublished data } \\
\text { contain records of only four captures of the House Mouse } \\
\text { (Mus musculus) and Black Rat (Rattus rattus) in } 15 \text { years of } \\
\text { monitoring. }\end{array}$ \\
\hline Fire & $\begin{array}{l}\text { Fire is a driver of spatial temporal variation in animal } \\
\text { abundance at Booderee National Park (Lindenmayer et al. } \\
2016 \text { a), and approximately half the park burnt in a wildfire in } \\
2003 \text { (Foster et al. 2017). However, species losses and } \\
\text { declines have occurred park-wide and not only in burnt but } \\
\text { long unburnt areas and across all vegetation types. Time since } \\
\text { fire as an independent process was not a key component in } \\
\text { path analysis for the Common Ringtail Possum. The decline } \\
\text { of the Long-nosed Bandicoot following an initial increase } \\
\text { could be associated with increasing time since fire (Fig 5). }\end{array}$ \\
\hline Exotic herbivore release & $\begin{array}{l}\text { There is no evidence of a significant increase in species such } \\
\text { as the European rabbit (Oryctolagus cuniculus). }\end{array}$ \\
\hline Food limitation & $\begin{array}{l}\text { There is no evidence of a decline in food availability for now } \\
\text { locally extinct mammals like the Common Ringtail Possum } \\
\text { and Greater Glider. Vegetation cover is broadly increasing in } \\
\text { the understorey and overstorey layers (Lindenmayer et al. } \\
\text { 2016b) where these animals feed. However, a decline in food } \\
\text { quality over this period is possible, and warrants investigation. }\end{array}$ \\
\hline $\begin{array}{l}\text { Consumption of poison } \\
\text { baits }\end{array}$ & $\begin{array}{l}\text { Some of the temporal trajectories or feeding traits of locally } \\
\text { extinct species are inconsistent with bait consumption. } \\
\text { Animals such as the Common Brushtail Possum are known to } \\
\text { consume baits (Dundas et al. 2014), but populations of this } \\
\text { species increased over time (Figure 4). The now extinct } \\
\text { Greater Glider does not descend to the ground where baits are } \\
\text { laid. Other species which have declined and spend time on the } \\
\text { ground may take baits (see Fairbridge et al. 2000; Dundas et }\end{array}$ \\
\hline
\end{tabular}




\begin{tabular}{|l|l|}
\hline & $\begin{array}{l}\text { al. 2014) and further exploration of such effects may be } \\
\text { warranted. }\end{array}$ \\
\hline Disease & $\begin{array}{l}\text { Disease is unlikely given the wide range of mammalian taxa } \\
\text { lost (from different classes and orders of mammals). We } \\
\text { found no evidence from repeated trapping or other surveys of } \\
\text { widespread morbidity resulting from disease or parasitism. No } \\
\text { known diseases affect multiple taxa in our study area, but } \\
\text { without further investigation, the role of disease in the } \\
\text { observed declines cannot be ruled out (Preece et al. 2017). }\end{array}$ \\
\hline Climate change & $\begin{array}{l}\text { Areas immediately outside Booderee National Park support } \\
\text { populations of all species lost from or declining in the reserve } \\
\text { (Villaseñor et al. 2014; Villaseñor et al. 2015). In addition, } \\
\text { there are no strong weather or climate effects for mammals } \\
\text { (Lindenmayer and Lane, unpublished data). However, there } \\
\text { may be climate change effects on the quality of leaf nutrients } \\
\text { for the foliage eating specialist, the Greater Glider (see } \\
\text { Kanowski 2001). }\end{array}$ \\
\hline Invasive plant species & $\begin{array}{l}\text { Control of invasive plant species such as Bitou Bush has been } \\
\text { largely effective and treatment protocols have limited short- } \\
\text { term effects on native mammals (Lindenmayer et al. 2017). In } \\
\text { addition, the invaded area is a small proportion of the park } \\
\text { and animals have been lost from areas not subject to weed } \\
\text { invasion or control. }\end{array}$ \\
\hline Irruptive dynamics & $\begin{array}{l}\text { This may be a plausible explanation for the increase and } \\
\text { decline of the Long-nosed Bandicoot which have been seen } \\
\text { elsewhere (Tyndale-Biscoe 2005). However, now locally } \\
\text { extinct species such as the Greater Glider and Common } \\
\text { Ringtail Possum or declining taxa like the Bush Rat are not } \\
\text { characterized by irruptive dynamics. }\end{array}$ \\
\hline
\end{tabular}

The preceding paragraphs have explored evidence for a series of potential drivers of decline, largely in isolation. However, we found non-linear patterns of temporal change for five of the 12 species. These patterns and the limited associations identified through path analysis, suggest that declines may be occurring in response to combined stressors, including those yet unidentified. Other studies have uncovered evidence of interactions between the fire and hunting efficiency of predators (Hradsky et al. 2017). Following major wildfires in 2003, we did not record a spike in bait take or sand plot records of foxes (Figure 3) or the Feral Cat, although this does not mean these predators did not consume more mammals after the fire. We suggest there is a need for additional investigation of potentially interacting factors in an 
attempt to identify the drivers of decline. As outlined in the following section, such investigations may include translocations of currently regionally extinct species to refill empty niches and help identify drivers of decline (Caughley and Gunn 1996). We also suggest there is a need to re-evaluate our understanding of the ecological interactions in native species assemblages, including those invaded by exotic predators (Doherty et al. 2015). New knowledge is needed of the types and strengths of different kinds of interactions: both trophic (predator-prey) and non-trophic (competitive (prey-prey) and perhaps even mutualistic), so that more comprehensive ecological networks can be derived (Melián et al. 2009). Only in this way might we realistically understand the complexity of whole-ofcommunity changes in response to management interventions such as those documented in this study (Kéfi et al. 2012). Finally, it is possible that we simply did not gather sufficient empirical data to allow us to identify causes of decline from among the multiple possible sources of temporal and spatial variation in the data. This is a sobering consideration given the intensive sampling completed over a prolonged period. Different kinds of monitoring with a different focus to those employed in our work may be required to better determine the driver/s of native mammal decline.

Isolation is one possible factor that was untested but which may have influenced our results. Booderee National Park is a peninsula and there has been considerable urbanization adjacent to the reserve. Peninsula effects (sensu Simpson 1964; Tubelis et al. 2007) may limit connectivity meaning that population declines and extinctions unable to be reversed by immigration. This may explain the ongoing extinctions that have occurred in Booderee National Park in the past, including the losses of the Spotted-tailed Quoll and Yellow-bellied Glider in the 1980s. This could also explain the unreversed declines in the Greater Glider and the Common Ringtail Possum observed during our monitoring work (see Figure 4). 


\section{General lessons and challenges in managing depleted assemblages when the drivers of}

\section{change remain elusive}

The rapid erosion of the mammal assemblages reported here took place within one of Australia's best managed protected areas where conservation biology principles have been actively applied to tackle a key process thought to threaten native mammal biodiversity. This is a classic example of an ecological surprise (sensu Lindenmayer et al. 2010; Anderson et al. 2017). These kinds of unexpected events are likely to become increasingly prevalent with growing human pressures on ecosystems, and present significant challenges to biodiversity managers, especially when the mechanisms of biodiversity decline remain unclear (e.g. the recent declines of invertebrates in the Northern Hemisphere (Vogel 2017)). Below we outline how these problems can be tackled and draw some general lessons for conservation and management.

Increase efforts to identify drivers of decline and modify management actions that may be leading to perverse outcomes. The temporal declines we documented are currently not explained by any clear mechanism, nor could they have been anticipated nor predicted on the basis of existing ecological knowledge or theory. Further assessment of potential drivers of decline is critical, although identifying unknown causes of declines can take a long time. For example, it took 15 years to identify the role of chytrid fungus in the worldwide demise of amphibians (Scheele et al. 2017b). Such assessments should include re-examining management practices that may have inadvertently had perverse effects. An important general principle with this lesson is to maintain and monitor "control areas" (such as adjacent offreserve environments, or nearby reserves) where a given management action is not implemented to provide contrasts in experimental studies and act as "insurance" in case of perverse outcomes. Our experience at Booderee National Park suggests that this is 
appropriate even when there seems to be a compelling case for implementing a particular management intervention (such as fox control).

$\underline{\text { Reconstruct depleted assemblages and re-fill vacant niches to test hypotheses of decline and }}$ increase management learning. Biodiversity loss invariably leaves depleted assemblages and vacant niches. Reintroduction and translocation programs may be required to rectify these problems. Such programs also can be used to help identify potential drivers of decline (Caughley and Gunn 1996). In the case of Booderee National Park, they could be used to test hypotheses about the cascading effects on populations of other species associated with refilling the large mammal predator niche (e.g. with the Spotted-tailed Quoll that was last seen in the reserve in the 1980s). The inherent danger of this option is that a lack of prey for re-established predators may result in elevated predation risks for other taxa, including those of conservation concern. A detailed risk assessment would be needed prior to such an action (e.g. see Dexter et al. 2012) including evaluation of interactions among species for proposed reintroductions (Plein et al. 2016). A further management action might be to reconstruct parts of the currently depleted arboreal marsupial assemblage, again through the use of experimental translocations, for currently locally extinct species such as the Greater Glider and Common Ringtail Possum. The complexity with this option is that the Greater Glider is now a nationally listed vulnerable species

\section{(http://www.environment.gov.au/biodiversity/threatened/nominations/comment/greater-}

glider) and experiments to test drivers of decline (and in which some individuals may perish) will need to clear ethical obstacles, particularly as the reasons for initial extinction remain unresolved. However, considering its increasingly threatened status, there is a greater imperative to conduct such experiments to determine drivers of decline.

Develop better early warning signals of decline. More work is needed to guide early interventions to prevent declines as well as better predict changes in populations of species, 
interactions between species, and in ecosystem conditions. In Booderee National Park, there were no early warning signs of the local extinction of, for example, the Greater Glider; the species' demise was rapid (over two years of monitoring, site occupancy crashed from $24 \%$ of monitoring sites to zero). Developing better early warning signals represents major challenges to those designing monitoring systems as the kinds of monitoring required to quantify declines may not help resolve drivers of those declines. We suggest there is a need to track (sometimes subtle) changes in the whole community rather than focusing on individual species. This is because many species are changing concurrently in divergent ways and tracking species individually may result in detecting changes too late - as was the case for the Greater Glider.

$\underline{\text { Recognize the pathway to recovery may be more complex than simply reversing the apparent }}$ initial drivers of decline. The traditional approach to the conservation of threatened biota is to identify the drivers of decline, instigate management actions to mitigate threatening processes, and recover target species. However, the work reported here suggests that removing an apparent initial threat (which may be mis-identified) is not always the pathway to species recovery. Such complexity is particularly challenging where the reasons underlying biodiversity loss remain unknown. In complex ecosystems, the ecological process that drove a particular decline may differ from the process currently limiting a species' abundance or distribution, particularly when a species has been in decline for many decades, and where threats have potentially altered the realized niche of the declining species (Scheele et al. 2017a).

\section{Conclusions}

We report significant declines and extinctions of native mammal biota in a well-managed protected area despite effective control of a key threat to native mammals. The temporal 
declines documented are currently not explained by any single mechanism, nor could they have been easily anticipated or predicted on the basis of ecological theory. Important challenges and general lessons emerging from this study include determining the best ways to manage biodiversity when drivers of species decline remain unclear and identifying strategies to manage novel assemblages of species. In particular, we suggest the need to employ experimentally-guided reintroductions and translocations to restore empty niches, reconstruct depleted guilds, and further test key hypotheses associated with declines. There is also a need to both: (1) reassess management actions that may be having perverse impacts and (2) develop more sensitive early warning signals to alert researchers and conservation managers of impending problems.

\section{REFERENCES}

Anderson, S.C., Branch, T.A., Cooper, A.B., Dulvya, N.K. 2017. Black-swan events in animal populations. Proceedings of the National Academy of Sciences 114, 3252-3257.

Australian Government. 2015. Threatened Species Strategy. Department of the Environment, Canberra, Australia.

Banks, P.B. 1999. Predation by introduced foxes on native bush rats in Australia: do foxes take the doomed surplus? Journal of Applied Ecology 36, 1063-1071.

Bergstrom, D.M., Lucieer, A., Kiefer, K., Wasley, J., Belbin, L., Pedersen, T.K., Chown, S.L. 2009. Indirect effects of invasive species removal devastate World Heritage Island. Journal of Applied Ecology 46, 73-81.

Braysher, M. 2017. Managing Australia's pest animals. A guide to strategic planning and effective management. CSIRO Publishing, Melbourne.

Caughley, G.C., Gunn, A. 1996. Conservation Biology in Theory and Practice. Blackwell Science, Cambridge, MA.

Dawson, T.J. 2000. Kangaroos, Biology of the Largest Marsupials. UNSW Press, Sydney.

Debus, S.J.S. 1997. A survey of the raptors of Jervis Bay National Park. Australian Birds 30, 29-44. Dexter, N., Ramsay, D.S.L., MacGregor, C., Lindenmayer, D.B. 2012. Predicting ecosystem wide impacts of wallaby management using a fuzzy cognitive map. Ecosystems 15, 1363-1379.

Doherty, T.S., Dickman, C.R., Nimmo, D., Ritchie, E.G. 2015. Multiple threats, or multiplying the threats? Interactions between invasive predators and other ecological disturbances. Biological Conservation 190, 60-68.

Dundas, S., Adams, P.J., Fleming, P.A. 2014. First in, first served: uptake of 1080 poison fox baits in south-west Western Australia. Wildlife Research 41, 117-126.

Fairbridge, D., Fisher, P., Busana, F., Pontin, K., Edwards, A., Johnston, M., Shaw, M. 2000. Observations of the behaviour of free-living bush rat Rattus fuscipes and southern brown bandicoot Isoodon obesulus at buried bait stations. Australian Mammalogy 22, 125-127. Foster, C., Barton, P., MacGregor, C., Robinson, N., Lindenmayer, D.B. 2017. Effects of a large wildfire on vegetation structure in a variable fire mosaic. Ecological Applications.

Foster, C.N., Barton, P.S., Sato, C.F., Wood, J.T., MacGregor, C.I., Lindenmayer, D.B. 2016. Herbivory and fire interact to affect forest understory habitat, but not its use by small vertebrates. Animal Conservation 19, 15-25. 
Garnett, S., Woinarski, J., Lindenmayer, D.B., Latch, P., editors. 2018. Recovering Australian Threatened Species: A Book of Hope. CSIRO Publishing, Melbourne.

Howard, J. 1989. Diet of Petaurus breviceps (Marsupilia: Petauridae) in a mosaic of coastal woodland and heath. Australian Mammalogy 12, 15-21.

Hradsky, B.A., Mildwaters, C., Ritchie, E.G., Christie, F., Di Stefano, J. 2017. Responses of invasive predators and native prey to a prescribed forest fire. J Mammal 98, 835-847.

Johnson, C.N., Balmford, A., Brook, B.W., Buettel, J.C., Galetti, M., Guangchun, L., Wilmshurst, J.M. 2017. Biodiversity losses and conservation responses in the Anthropocene. Science 356, 270 275.

Kanowski, J. 2001. Effects of elevated $\mathrm{CO}_{2}$ on the foliar chemistry of seedlings of two rainforest trees from north-east Australia: Implications for folivorous marsupials. Austral Ecology 26, 165-172.

Kéfi, S., Berlow, E.L., Wieters, E.A., Navarrete, S.A., Petchey, O.L., Wood, S.A., Brose, U. 2012.

More than a meal... integrating non-feeding interactions into food webs. Ecology Letters 15, 291-300.

Kinnear, J.E., Onus, M.L., Bromilow, R.N. 1988. Fox control and rock-wallaby population dynamics. Australian Wildlife Research 15, 435-450.

Korpimaki, E. 1985. Rapid tracking of microtine populations by their avian predators: possible evidence for stabilizing predation. Oikos 44, 281-284.

Kovacs, E., Crowther, M.S., Webb, J.K., Dickman, C.R. 2012. Population and behavioural responses of native prey to alien predation. Oecologia 168, 947-957.

Lampert, A., Hastings, A., Grosholz, E.D., Jardine, S.L., Sanchirico, J.N. 2014. Optimal approaches for balancing invasive species eradication and endangered species management. Science 344, 10281031.

Lazenby, B.T., Mooney, N.J., Dickman, C.R. 2015. Effects of low-level culling of feral cats in open populations: a case study from the forests of southern Tasmania. Wildlife Research 41, 407-420.

Legge, S., Murphy, B.P., McGregor, H., Woinarski, J.C.Z., Augusteyn, J., Ballard, G., Maxwell, M., Morris, K., Wayne, A.F. 2017. Enumerating a continental-scale threat: how many feral cats are in Australia? Biological Conservation 206, 293-303.

Lindenmayer, D.B., Blanchard, W., MacGregor, C., Barton, P., Banks, S.C., Crane, M., Michael, D., Okada, S., Berry, L., Gill, A.M. 2016a. Temporal trends in mammal responses to fire reveal complex effects of fire regime attributes. Ecological Applications 26, 557-573.

Lindenmayer, D.B., Burgman, M.A. 2005. Practical Conservation Biology. CSIRO Publishing, Melbourne.

Lindenmayer, D.B., Candy, S.G., Banks, S.C., Westgate, M., Ikin, K., Pierson, J., Tulloch, A., Barton, P. 2016b. Do temporal changes in vegetation structure predict changes in bird occurrence additional to time since fire? Ecological Applications 26, 2267-2279.

Lindenmayer, D.B., Hunter, M. 2010. Some guiding concepts for conservation biology. Conservation Biology 24, 1459-1468.

Lindenmayer, D.B., Likens, G.E., Krebs, C.J., Hobbs, R.J. 2010. Improved probability of detection of ecological "surprises". Proceedings of the National Academy of Sciences 107, 21957-21962.

Lindenmayer, D.B., MacGregor, C., Dexter, N., Fortescue, M. 2014. Booderee National Park: The Jewel of Jervis Bay. CSIRO Publishing, Melbourne.

Lindenmayer, D.B., MacGregor, C., Dexter, N., Fortescue, M., Cochrane, P. 2013. Booderee National Park management: Connecting science and management. Ecological Management \& Restoration 14, $2-10$.

Lindenmayer, D.B., MacGregor, C., Welsh, A.W., Donnelly, C.F., Brown, D. 2008. The use of hollows and dreys by the common ringtail possum (Pseudocheirus peregrinus) in different vegetation types. Australian Journal of Zoology 56, 1-11.

Lindenmayer, D.B., Wood, J., MacGregor, C., Hobbs, R.J., Catford, J.A. 2017. Non-target impacts of weed control on birds, mammals, and reptiles. Ecosphere 8, e01804.

Marlow, N., Thomas, A., Macmahon, J., Lawson, Y., Hitchen, J., Angus, O., Berry, O. 2015. Cats

(Felis catus) are more abundant and are the dominant predator of woylies (Bettongia penicillata) after sustained fox (Vulpes vulpes) control. Australian Journal of Zoology 63, 18-27.

May, R.M. 1981. Models for two interacting populations, in May, R.M. (editor, Theoretical Ecology, Principles and Applications. Blackwell Scientific Publications, Oxford, pp. 78-104 
McGregor, H.W., Legge, S., Jones, M.E., Johnson, C.N. 2014. Landscape Management of Fire and Grazing Regimes Alters the Fine-Scale Habitat Utilisation by Feral Cats. PLoS ONE 9, e109097. Meek, P.D., Triggs, B. 1998. The food of foxes, dogs and cats on two peninsulas in Jervis Bay, New South Wales. Proceedings of the Linnean Society of New South Wales 120, 117-127.

Melián, C.J., Bascompte, J., Jordano, P., Křivan, V. 2009. Diversity in a complex ecological network with two interaction types. Oikos 118, 122-130.

Murray, A.J., Poore, R.N., Dexter, N. 2006. Project deliverance - the response of "critical weight range" mammals to effective fox control in mesic forest habitats in far East Gippsland, Victoria. Department of Sustainability and Environment, Melbourne, Victoria.

Pardini, E.A., Drake, J.M., Chase, J.M., Knight, T.M. 2009. Complex population dynamics and control of the invasive biennial Alliaria petiolata (garlic mustard). Ecological Applications 19, $387-$ 397.

Plein, M., Bode, M., Moir, M.L., Vesk, P.A. 2016. Translocation strategies for multiple species depend on interspecific interaction type. Ecological Applications 26, 1186-1197.

Preece, N.D., Abell, S.E., Grogan, L., Wayne, A., Skerratt, L.F., Van Oosterzee, P., Shima, A.L., Daszak, P., Field, H., Reiss, A. 2017. A guide for ecologists: Detecting the role of disease in faunal declines and managing population recovery. Biological Conservation 214, 136-146.

Roberts, M.W., Dexter, N., Meek, P.D., Hudson, M., Buttemer, W.A. 2006. Does baiting influence the relative composition of the diet of foxes? Wildlife Research 33, 481-488.

Scheele, B.C., Foster, C.N., Banks, S.C., Lindenmayer, D.B. 2017a. Niche contractions in declining species: mechanisms and consequences. Trends in Ecology and Evolution 32, 346-355.

Scheele, B.C., Skerratt, L.F., Grogan, L.F., Hunter, D.A., Clemann, N., McFadden, M., Newell, D., Hoskin, C.J., Gillespie, G.R., Heard, G.W. 2017b. After the epidemic: Ongoing declines,

stabilizations and recoveries in amphibians afflicted by chytridiomycosis. Biological Conservation 206, 37-46.

Shipley, B. 2009. Confirmatory path analysis in a general multilevel context. Ecology 90, 363-368. Simpson, G.G. 1964. Species density of North American recent mammals. Systematic Zoology 13, 57-73.

Stirnemann, I.A., Ikin, K., Gibbons, P., Blanchard, W., Lindenmayer, D.B. 2014. Measuring habitat heterogeneity reveals new insights into bird community composition. Oecologia 177, 733-746. Taylor, R. 1979. How the Macquarie Island Parakeet became extinct. New Zealand Journal of Ecology 2, 42-45.

Tilman, D., Clark, M., Williams, D.R., Kimmell, K., Polasky, S., Packer, C. 2017. Future threats to biodiversity and pathways to their prevention. Nature 546, 65-72.

Triggs, B., Brunner, H., Cullen, J.M. 1984. The food of fox, dog and cat in Croajingalong National Park, south-eastern Victoria. Australian Wildlife Research 11, 491-499.

Tubelis, D.P., Lindenmayer, D.B., Cowling, A. 2007. The peninsula effect on bird species in native eucalypt forests in a wood production landscape in Australia. Journal of Zoology 271, 11-18.

Tyndale-Biscoe, H. 2005. Life of Marsupials. CSIRO Publishing, Melbourne.

Villaseñor, N.R., Blanchard, W., Driscoll, D.A., Gibbons, P., Lindenmayer, D.B. 2015. Strong influence of local habitat structure on mammals reveals mismatch with edge effects models.

Landscape Ecology 30, 229-245.

Villaseñor, N.R., Driscoll, D.A., Escobar, M.A.H., Gibbons, P., Lindenmayer, D.B. 2014.

Urbanization impacts on mammals across urban-forest edges and a predictive model of edge effects.

PLOS One 9, e97036.

Vogel, G. 2017. Where have all the insects gone? Science 356, 576-579.

Walsh, J.C., Wilson, K.A., Benshemesh, J., Possingham, H.P. 2012. Unexpected outcomes of invasive predator control: the importance of evaluating conservation management actions. Animal

Conservation 15, 319-328.

Wayne, A.F., Maxwell, A.A., Ward, C.G., Wayne, J.C., Vellios, C.V., Wilson, I.J. 2017. Recoveries and cascading declines of native mammals associated with control of an introduced predator. $\mathrm{J}$

Mammal 98, 489-501.

Woinarski, J.C., Burbidge, A.A., Harrison, P.L. 2015. Ongoing unraveling of a continental fauna: Decline and extinction of Australian mammals since European settlement. Proc Natl Acad Sci USA $112,4531-4540$. 
WWF Australia. 2008. Building Nature's Safety Net: Top 10 reserves of the first decade of the National Reserve System.

Zavaleta, E.S., Hobbs, R.J., Mooney, H.A. 2001. Viewing invasive species removal in a wholeecosystem context. Trends in Ecology \& Evolution 16, 454-459.

Zipkin, E.F., Kraft, C.E., Cooch, E.G., Sullivan, P.J. 2009. When can efforts to control nuisance and invasive species backfire? Ecological Applications 19, 1585-1595. 